\title{
Nutritional and eating education improves knowledge and practice of patients with type 2 diabetes concerning dietary intake and blood glucose control in an outlying city of China
}

\author{
Huan Wang ${ }^{1}$, Zhenfeng Song ${ }^{1}$, Yanhui $\mathrm{Ba}^{2}$, Lin Zhu ${ }^{1}$ and Ying Wen ${ }^{1, *}$ \\ 'Department of Nutrition and Food Hygiene, School of Public Health, Harbin Medical University, 157 Baojian \\ Road, Nangang District, 150086 Harbin, People's Republic of China: ${ }^{2}$ Hulunbeier Vocational Technical \\ College, Hulunbeier, People's Republic of China
}

Submitted 17 January 2013: Final revision received 2 July 2013: Accepted 28 August 2013: First published online 14 October 2013

\begin{abstract}
Objective: To describe the knowledge, attitudes and practices of type 2 diabetics in Yakeshi City and to assess the effect of implementation of nutritional and eating education in enhancing knowledge and practices regarding a healthy diet. Design: A questionnaire-based survey was conducted with 162 diabetics to determine their nutrition knowledge, attitudes and practices; fifty-four participants received nutritional and eating education for 6 months. Diabetes-related nutrition knowledge, awareness, practice accuracy, dietary intake and glycaemic control were assessed before and after education.

Setting: Yakeshi, a remote city in northern China.

Subjects: A total of 162 type 2 diabetics recruited from three hospitals, fifty-four of whom were selected randomly to receive education.

Results: Among the 162 respondents, most diabetics (75\%) considered that controlling diet was important in the methods of controlling blood glucose. Scores for knowledge, practices and overall KAP (knowledge-attitude-practice) were low, but scores for attitude were high. Participants with diabetes education experiences, practice duration over 1 year or high education level all had higher scores for KAP $(P<0.001, P<0.05$ and $P<0.001$, respectively) than their counterparts. After education, patients' nutrition knowledge, awareness and practice accuracy improved significantly $(P<0 \cdot 05)$. The rates of patients with recommended daily intake of vegetables, grains and dairy were boosted $(P<0 \cdot 05)$. Various nutrient intakes increased $(P<0 \cdot 05)$ but not protein, Fe, Zn and Se. Significant improvements were also found in glycaemic control $(P<0 \cdot 05)$.

Conclusions: Diabetics in Yakeshi had positive attitudes, but relatively poor nutrition knowledge and practices. Nutritional and eating education was effective in improving diabetics' nutrition knowledge and practices, and this optimal practice helped them control blood glucose effectively.
\end{abstract}

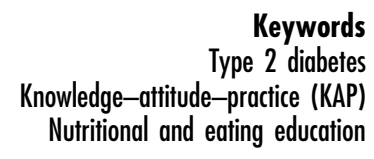

Diabetes, particularly type 2 diabetes mellitus, is a major public health concern worldwide ${ }^{(1)}$. In parallel with economic development and lifestyle changes in China, the Chinese diabetic population has increased rapidly in recent years, alongside the steady growth in diabetes prevalence globally. According to a recently published survey, $9 \cdot 7 \%$ of the adult Chinese population has diabetes ${ }^{(2)}$. Because diabetes complications can be prevented or delayed by the rigorous control of blood glucose level ${ }^{(3)}$, it is well established that nutritional intervention is essential to improve blood glucose control in people with diabetes ${ }^{(4)}$. Diabetics should pay sufficient attention to diabetes nutrition therapy; however, undesirable clinical effects occur due to deficiencies that still exist in nutrition knowledge ${ }^{(5)}$. Education is an effective way to make up for the deficiency ${ }^{(6)}$, while in outlying areas of China, formal diabetes nutritional and eating education is lacking. In the present study, a questionnaire-based pilot survey was conducted in Yakeshi, a remote city in northern China, to assess the nutrition knowledge, attitudes and practices of type 2 diabetics in relation to dietary intake and blood glucose control and to evaluate the effect of implementation of nutritional and eating education on healthy diet and self-management of diabetes.

\section{Methods}

\section{Participants and study design}

A questionnaire-based pilot survey of patients with type 2 diabetes in Yakeshi was conducted from April 2010 to 
April 2011. In the present study, 109 males and fifty-three females were selected from the endocrine out-patient and in-patient departments of three hospitals (Inner Mongolia Forestry General Hospital, Yakeshi Hospital and Yakeshi Mongolia Hospital). The inclusion criteria were patients identified with type 2 diabetes mellitus according to the new diabetes classification and diagnostic criteria (specified by the American Diabetes Association in 1997). Investigators were recruited from hospital nurses and trained by the researchers to give a verbal explanation of the questionnaire for patients.

To describe the knowledge, attitudes and practices of patients with type 2 diabetes, 162 diabetics participated in the knowledge-attitude-practice (KAP) questionnaire survey. Participants were conscious and consented to the survey project. Scores for knowledge, attitudes and practices were assessed by questionnaire and face-to-face interviews. For assessing the effect of nutritional and eating education, fifty-four patients were randomly selected from the 162 interviewees and signed a written informed consent before accepting a 6-month nutritional and eating education. Education assessment questionnaires and $24 \mathrm{~h}$ recalls were completed before and after education, and fasting blood glucose and $2 \mathrm{~h}$ postprandial blood glucose were also checked. Multiple methods were applied in the education programme. (i) Nutrition lectures were given, during which food exchange lists and nutrition knowledge materials were distributed to every participant and food and nutrition hygiene knowledge was explained using real food and food models. Lectures were controlled to within $1 \mathrm{~h}$ and $10-15 \mathrm{~min}$ were left for answering questions and for discussion. (ii) According to the knowledge misunderstandings that occurred in the questionnaire, wrong answers were explained and the relevant nutrition knowledge was given to the patients face-to-face. (iii) Patients and their families were taught to develop individualized nutrition therapies based on their height, weight, labour intensity, blood glucose, blood lipids, renal function, liver function and personal eating habits according to the concept of food exchange portion. (iv) Follow-up telephone calls were made once per month to understand patients' exercise, drugs and treatment situation and to solve their actual nutrition issues.

\section{Dietary intake data}

Both a gravimetric method and a standardized $24 \mathrm{~h}$ dietary recall were used to investigate patients' dietary and nutrient intakes during $3 \mathrm{~d}$ at baseline and follow-up. All foods and drinks consumed in the previous $24 \mathrm{~h}$ were recorded and the amounts of different food items that were mixed in one dish were recorded respectively. Local food photographs, portion-size images and volumetric vessels were used to increase the accuracy of the recall from the previous $24 \mathrm{~h}$. Interviewers coded dietary data according to the Chinese Coding Manual (China Addendum to the INTERMAP Nutrition Mamual of Operations). The nutritional composition of ingredients was computed using the Chinese food composition tables ${ }^{(7)}$.

\section{Questionnaire design}

The KAP questionnaire was designed on the basis of reviewing extensive literature ${ }^{(8)}$ and was examined by experts from university departments of Nutrition and Food Hygiene, Epidemiology and Statistics. The questionnaire was used in a pre-study to test its reliability and validity and corresponding revision of two items was made according to the pre-study results.

The KAP questionnaire was divided into four sections and comprised a series of questions pertaining to sociodemographic characteristics, basic nutrition knowledge, attitudes towards nutrition behaviours and practice characteristics. The sociodemographic part of the instrument included questions on demographic characteristics, diseaserelated characteristics, and actual and expected sources of nutrition knowledge (in the nutrition knowledge sources section, participants could choose more than one option). For assessing basic nutrition knowledge, participants were asked fifteen questions (maximum accumulated score was 23) relating to ideal weight, treatment, hypoglycaemia, food exchange portion, complications, diet, etc. Some issues required detailed answers (e.g. common symptoms of diabetes, common complications of diabetes, concept of food exchange portion, daily food intake and the energy distribution ratio of three meals, calculation method of ideal weight, symptoms and treatment measures of hypoglycaemia, taboo foods of diabetes and glycaemic control method) and these items were assessed with 2 points as a desirable score, the other questions scoring 1 point. Validity and reliability were calculated. The content validation index was 0.923 and Cronbach's $\alpha$ index was 0.909 . For attitudes towards nutrition behaviours, respondents were asked to use a two-point ordinal scale (rating scale from 0 to 2, $2=$ 'yes' and $0=$ 'no') in seven questions, including changing unhealthy diet, losing weight, accepting diabetes education, etc. Validity and reliability were calculated. The content validation index was 0.879 and Cronbach's $\alpha$ index was $0 \cdot 813$. In the fourth set of questions, we assessed nutrition practices: this section had eighteen questions relating to general diet, weight check, blood-glucose check, exercise, frequency of food intakes, etc. The maximum score was 23 including five questions scoring 2 points ('How often do you monitor your blood glucose?', 'How often do you monitor your body weight?', 'How often do you drink milk?', 'How often do you eat vegetables?' and 'How often do you eat fruits?'), other items were assessed with 1 point as a desirable score. Validity and reliability were calculated. The content validation index was $0 \cdot 880$ and Cronbach's $\alpha$ index was $0 \cdot 773$. The summation of knowledge, attitude and practice grades was equal to the total KAP score of the participants. The proportion of nutrition knowledge, active attitude and optimal practice for each question was calculated as the 
rate of the number of people who gave a correct (positive) answer in the total answers.

The education assessment questionnaire was simplified from the above questionnaire. The sociodemographic part and attitude section were removed and fourteen typical questions, including seven from the knowledge section and seven from the practice section, were selected.

\section{Statistical analysis}

Statistical analysis was done using the statistical software package SPSS for Windows version 16.0. The level of significance was established as a two-sided $P$ value of $<0 \cdot 05$. Data were reported as mean and standard deviation (for continuous variables) or as number and percentage (for categorical variables), and were compared using the Student $t$ test or the $\chi^{2}$ test.

\section{Results}

\section{Basic characteristics of the study participants}

A total of 162 patients were interviewed and all returned the questionnaires after proper answering. Of these patients, eighty-five $(52 \cdot 47 \%)$ were from the city and seventy-seven $(47 \cdot 53 \%)$ were from the country. The number of male patients was much higher than that of female patients: $109(67 \cdot 28 \%)$ and fifty-three $(32 \cdot 72 \%)$, respectively. Patients over the age of 50 years accounted for $76.55 \%$ and $54.32 \%$ of all participants had only primary education. The distribution of diabetic patients according to their sociodemographic characteristics is shown in Table 1.

The disease-related characteristics of the participants were assessed and showed that 133 had a family history of diabetes, $79 \cdot 12 \%$ of the interviewees had varying degrees of diabetic complications, 123 patients had a practice duration of over 1 year and $75 \cdot 31 \%$ of the patients considered diet control as an important method of controlling blood glucose (Table 2).

\section{Diabetes patients' actual and expected sources of nutrition information}

Most of the patients had no diabetes nutritional education experience; their sources of nutritional information were extensive but irregular. Medical workers was the main actual source, accounting for $64 \cdot 20 \%$; other sources were ward-mates (28.40\%), friends and relatives (17.90\%), radio and television $(20 \cdot 37 \%)$, newspapers and magazines $(13 \cdot 58 \%)$, books $(30 \cdot 25 \%)$, nutrition lectures $(8 \cdot 64 \%)$ and others $(2 \cdot 47 \%)$. Their expected sources were medical workers $(88 \cdot 89 \%)$, nutritionists $(6 \cdot 17 \%)$, books $(3 \cdot 09 \%)$ and others $(1 \cdot 85 \%)$.

\section{Diabetic-related knowledge, attitudes and practices of participants}

The mean overall KAP score for the patients who had diabetes education experience was 39·00 (SD 5·38),
Table 1 General characteristics of 162 diabetes patients in Yakeshi, a remote city in northern China, April 2010-April 2011

\begin{tabular}{lrr}
\hline Characteristic & $n$ & $\%$ \\
\hline Area & & \\
$\quad$ Urban & 85 & $52 \cdot 47$ \\
$\quad$ Rural & 77 & $47 \cdot 53$ \\
Sex & & \\
$\quad$ Male & 109 & $67 \cdot 28$ \\
$\quad$ Female & 53 & $32 \cdot 72$ \\
Age (years) & & \\
30-39 & 10 & $6 \cdot 17$ \\
$40-49$ & 28 & $17 \cdot 28$ \\
$50-59$ & 57 & $35 \cdot 19$ \\
$60-69$ & 47 & $29 \cdot 12$ \\
$\quad \geq 70$ & 20 & $12 \cdot 24$ \\
Educational status & & \\
Primary & 88 & $54 \cdot 32$ \\
Secondary & 40 & $24 \cdot 69$ \\
$\quad$ Tertiary & 3 & $20 \cdot 99$ \\
Family income (per month) & & \\
$\quad<1000$ Yuan & 30 & $18 \cdot 52$ \\
1000-2000 Yuan & 85 & $52 \cdot 76$ \\
$\quad>2000$ Yuan & 47 & $28 \cdot 72$ \\
\hline
\end{tabular}

Table 2 Disease-related characteristics of 162 diabetes patients in Yakeshi, a remote city in northern China, April 2010-April 2011

\begin{tabular}{|c|c|c|}
\hline Characteristic & $n$ & $\%$ \\
\hline \multicolumn{3}{|l|}{ Family history } \\
\hline Yes & 133 & $82 \cdot 10$ \\
\hline No & 29 & $17 \cdot 90$ \\
\hline \multicolumn{3}{|l|}{ BMI $\left(\mathrm{kg} / \mathrm{m}^{2}\right)$} \\
\hline$<18.5$ & 3 & $1 \cdot 85$ \\
\hline $18 \cdot 5-24 \cdot 9$ & 53 & $32 \cdot 72$ \\
\hline $25 \cdot 0-29 \cdot 9$ & 62 & $38 \cdot 27$ \\
\hline $30 \cdot 0-34 \cdot 9$ & 44 & $27 \cdot 16$ \\
\hline $35 \cdot 0-39 \cdot 9$ & 0 & 0.00 \\
\hline$\geq 40 \cdot 0$ & 0 & 0.00 \\
\hline \multicolumn{3}{|l|}{ Duration of practice (years) } \\
\hline$<1$ & 39 & $24 \cdot 07$ \\
\hline $1-5$ & 54 & 33.33 \\
\hline $6-10$ & 41 & $25 \cdot 31$ \\
\hline $11-15$ & 17 & $10 \cdot 49$ \\
\hline$>15$ & 11 & $6 \cdot 80$ \\
\hline \multicolumn{3}{|l|}{ Diabetes complication } \\
\hline Yes & 128 & $79 \cdot 12$ \\
\hline No & 34 & $20 \cdot 88$ \\
\hline \multicolumn{3}{|l|}{ Glycaemic control methods } \\
\hline Drugs + exercise + diet control & 47 & $29 \cdot 01$ \\
\hline Drugs + diet control & 66 & $40 \cdot 74$ \\
\hline Drugs + exercise & 9 & $5 \cdot 56$ \\
\hline Drugs & 23 & $14 \cdot 20$ \\
\hline Diet control & 9 & $5 \cdot 56$ \\
\hline Other methods & 8 & 4.93 \\
\hline
\end{tabular}

'Family history' means whether patients' relatives had had diabetes; 'Duration of practice' refers to the length of time that patients had had diabetes.

significantly higher $(P<0 \cdot 001)$ than for those without, who had a mean score of 31.00 (SD 7.94); this difference also occurred in knowledge score $(P<0.05)$ and practice score $(P<0 \cdot 001)$, but the attitude score was not significantly different between these two groups $(P>0 \cdot 05)$. Patients with $>1$ year of practice duration were more likely to have a higher practice score (mean 15.76 (SD 3.72); $P<0.05$ ) and KAP score (mean $32 \cdot 41$ (SD 7.63); $P<0 \cdot 05$ ) compared 
Table 3 Knowledge, attitude and practice scores according to area, diabetes education experience, duration of practice and educational status among 162 diabetes patients in Yakeshi, a remote city in northern China, April 2010-April 2011

\begin{tabular}{|c|c|c|c|c|c|c|c|c|c|}
\hline \multirow[b]{2}{*}{ Characteristic } & \multirow[b]{2}{*}{$n$} & \multicolumn{2}{|c|}{ Knowledge } & \multicolumn{2}{|c|}{ Attitude } & \multicolumn{2}{|c|}{ Practice } & \multicolumn{2}{|c|}{ KAP } \\
\hline & & Mean & SD & Mean & SD & Mean & SD & Mean & SD \\
\hline \multicolumn{10}{|l|}{ Area } \\
\hline Urban & 85 & $10 \cdot 05$ & $5 \cdot 38$ & $6 \cdot 40$ & 1.57 & $15 \cdot 09$ & $3 \cdot 34$ & $31 \cdot 54$ & $8 \cdot 20$ \\
\hline Rural & 77 & $9 \cdot 74$ & $5 \cdot 00$ & $6 \cdot 58$ & $1 \cdot 36$ & $15 \cdot 53$ & $4 \cdot 30$ & $31 \cdot 86$ & $7 \cdot 95$ \\
\hline$t$ & & \multirow{2}{*}{\multicolumn{2}{|c|}{$\begin{array}{r}0.375 \\
>0.05\end{array}$}} & \multicolumn{2}{|c|}{-0.796} & \multirow{2}{*}{\multicolumn{2}{|c|}{-0.719}} & \multicolumn{2}{|c|}{-0.249} \\
\hline$P$ & & & & & & & & & \\
\hline \multicolumn{10}{|c|}{ Diabetes education experience } \\
\hline Yes & 14 & $12 \cdot 93$ & $4 \cdot 78$ & $7 \cdot 07$ & 0.92 & $19 \cdot 00$ & $2 \cdot 75$ & $39 \cdot 00$ & $5 \cdot 38$ \\
\hline No & 148 & $9 \cdot 61$ & $5 \cdot 15$ & $6 \cdot 43$ & $1 \cdot 50$ & $14 \cdot 95$ & $3 \cdot 78$ & $31 \cdot 00$ & $7 \cdot 94$ \\
\hline$t$ & & \multicolumn{2}{|c|}{$2 \cdot 316$} & \multicolumn{2}{|c|}{$1 \cdot 560$} & \multicolumn{2}{|c|}{3.905} & \multicolumn{2}{|c|}{3.687} \\
\hline$P$ & & & & & & & & & \\
\hline \multicolumn{10}{|c|}{ Duration of practice (years) } \\
\hline$<1$ & 39 & $8 \cdot 74$ & $6 \cdot 07$ & $6 \cdot 85$ & $1 \cdot 37$ & $13 \cdot 85$ & $4 \cdot 00$ & $29 \cdot 44$ & $9 \cdot 02$ \\
\hline$>1$ & 123 & $10 \cdot 27$ & $4 \cdot 84$ & $6 \cdot 37$ & $1 \cdot 49$ & $15 \cdot 76$ & $3 \cdot 72$ & $32 \cdot 41$ & $7 \cdot 63$ \\
\hline$t$ & & \multicolumn{2}{|c|}{-1.608} & \multicolumn{2}{|c|}{$1 \cdot 758$} & \multicolumn{2}{|c|}{$-2 \cdot 753$} & \multicolumn{2}{|c|}{$-2 \cdot 025$} \\
\hline$P$ & & \multicolumn{2}{|c|}{$>0.05$} & \multicolumn{2}{|c|}{$>0.05$} & \multicolumn{2}{|c|}{$<0.05$} & \multicolumn{2}{|c|}{$<0.05$} \\
\hline \multicolumn{10}{|c|}{ Educational status } \\
\hline Primary & 88 & $7 \cdot 82$ & $3 \cdot 87$ & $6 \cdot 40$ & $1 \cdot 62$ & $14 \cdot 98$ & $3 \cdot 80$ & $29 \cdot 19$ & 6.58 \\
\hline Secondary & 40 & $10 \cdot 38$ & $5 \cdot 36$ & $6 \cdot 50$ & $1 \cdot 32$ & $15 \cdot 45$ & $4 \cdot 14$ & $32 \cdot 32$ & $8 \cdot 72$ \\
\hline Tertiary & 34 & $14 \cdot 74$ & $4 \cdot 67$ & $6 \cdot 71$ & $1 \cdot 24$ & $15 \cdot 97$ & $3 \cdot 74$ & $37 \cdot 41$ & $7 \cdot 87$ \\
\hline$F$ & & \multicolumn{2}{|c|}{$29 \cdot 962$} & \multicolumn{2}{|c|}{0.537} & \multicolumn{2}{|c|}{$0 \cdot 846$} & \multicolumn{2}{|c|}{$15 \cdot 198$} \\
\hline$P$ & & \multicolumn{2}{|c|}{$<0.001$} & \multicolumn{2}{|c|}{$>0.05$} & \multicolumn{2}{|c|}{$>0.05$} & & \\
\hline
\end{tabular}

KAP, overall knowledge-attitude-practice.

with those with a practice duration of $<1$ year (mean $13 \cdot 85$ (SD 4.00) and mean 29.44 (SD 9.02), respectively); however, knowledge and attitude scores showed no significant differences between these two groups $(P>0 \cdot 05)$. There was a significant difference in KAP score according to educational status, with patients who had higher education level scoring significantly higher than those with lower education level $(P<0 \cdot 001)$; the same was true for knowledge score $(P<0 \cdot 001)$, but no significant differences by education were found in attitude and practice scores $(P>0 \cdot 05)$. The results showed no evidence of an association between knowledge $(P>0.05)$, attitude $(P>0.05)$, practice $(P>0.05)$ or KAP $(P>0.05)$ scores and urban/rural area (Table 3 ).

\section{Comparison of baseline and follow-up}

By the end of the education, after the exclusion of twelve patients who were lost to follow-up (nine did not leave their telephone number voluntarily and three changed their telephone number later), forty-two patients (female thirteen, male twenty-nine; aged 35-74 years; five newly diagnosed ( $<1$ year of practice duration) and the others with diabetes duration of 1-18 years) were left.

On analysing the responses, the number of patients who answered correctly was higher at the final follow-up compared with baseline. Awareness of most questions was significantly $(P<0 \cdot 05)$ higher at the end of the study as shown in Table 4; however, intake of vegetables showed no improvement $(P>0 \cdot 05)$.

Table 5 shows that, before education, most patients' daily nutrient intakes were seriously inadequate compared with the Recommended Nutrient Intakes (RNI), with vitamin A, vitamin $\mathrm{C}$ and $\mathrm{Ca}$ intakes even lower than one-third of the RNI. After the intervention, the increment in protein, $\mathrm{Fe}, \mathrm{Zn}$ and Se intakes was not significant, while lipids, carbohydrate, energy, fibre, vitamin A, thiamin, riboflavin, vitamin $\mathrm{C}$, vitamin $\mathrm{E}, \mathrm{Ca}$ and $\mathrm{Mg}$ intakes increased significantly $(P<0 \cdot 05)$.

It can be seen from Table 6 that the rate of patients having a proper food intake was low before the intervention. After the nutritional and eating education, the situation improved and significant improvements were found in the rate of patients with recommended daily intakes of vegetables, grains, dairy and fruit.

Compared with baseline, after the nutrition intervention both fasting blood glucose and $2 \mathrm{~h}$ postprandial blood glucose were decreased significantly $(P<0 \cdot 05$; Table 7$)$.

\section{Discussion}

\section{Status of nutrition knowledge, attitudes and practices of patients with diabetes}

It can be seen from the survey results that diabetes patients were mostly concentrated in the elderly, with relatively low educational level, that most patients were overweight and had varying degrees of complications. Inappropriate nutrition is a significant causative factor for type 2 diabetes $^{(9)}$. In the baseline survey, where $75.31 \%$ of the participants said to control blood glucose by controlling diet, they have realized the importance of nutrition therapy for diabetes control; however, lacking professional guidance 
leads to misunderstandings on foods and then makes treatment ineffective. According to a survey in the UK, patients understood and were able to achieve the dietary changes suggested ${ }^{(10)}$. Proper nutrition suggestions to diabetics are necessary. In this pilot survey, we found that the 162 patients' actual nutrition information sources are extensive but irregular. They got information mainly from medical workers, accounting for $64 \cdot 20 \%$, and medical staff was also their main expected information source. It can be seen that diabetics trusted medical workers and wanted to get proper diabetes treatment principles from them, especially nutrition therapy guidance. Medical practitioners have an obligation to disseminate diabetesrelated nutrition knowledge among patients to enable them to master the nutrition therapy methods during hospitalization and lay a good foundation for the implementation of nutrition therapy after discharge. It is indispensable to spread nutrition knowledge among medical and nursing staff. Moreover, nutritional and eating education should be developed in communities ${ }^{(11)}$. Enhancing the message via diverse methods, such as nutrition lectures, books, newspapers, television, radio and community activities, can make patients form healthy eating habits, thus achieving optimal clinical effect. In the USA, diabetes self-management education is recommended with national standards and provided by professional diabetes educators other than physicians ${ }^{(12)}$.

Data from the KAP survey showed that the patients who had diabetes education experience had significantly higher scores in knowledge, practice and total KAP than those without diabetes education experience. These findings are in keeping with other literature, which displayed that educated patients' knowledge on diet is significantly improved compared with patients not receiving intensive education $^{(6)}$. It is well understood that formal diabetes nutritional and eating education can improve patients' KAP mastery and further affect their nutrition behaviours. Patients with longer diabetes duration had significantly higher practice scores than those with shorter practice experience. This may because the recurrence of diabetes, increase of diabetes complications or opportunities for exchanges between ward-mates make them know more about correct nutrition practices for diabetes, while without formal diabetes nutritional and eating education, there are no significant differences in attitude, knowledge and KAP scores. The survey score results also indicated that patients with higher educational level had significantly higher KAP score than less educated ones, with also a significantly higher score in one parameter: knowledge. Education status influences patients' KAP and is crucial to diabetes; a study carried by Nilsson et al. found that diabetics who were less educated had $40 \%$ excess mortality compared with those were highly educated ${ }^{(13)}$. In the present study there was no disparity between urban and rural regions of the city in scores on knowledge, attitudes, practices and total KAP. It has been proven that diabetes-related 
Table 5 Comparison of baseline and follow-up daily nutrient intakes of diabetes patients $(n 42)$ in Yakeshi, a remote city in northern China, April 2010-April 2011

\begin{tabular}{|c|c|c|c|c|c|c|c|c|c|c|}
\hline \multirow[b]{3}{*}{ Nutrients and energy } & \multicolumn{4}{|c|}{ Baseline } & \multicolumn{4}{|c|}{ Follow-up } & \multirow[b]{3}{*}{$t$} & \multirow[b]{3}{*}{$P$} \\
\hline & \multicolumn{2}{|c|}{ Intake } & \multicolumn{2}{|c|}{ Contribution to RNI (\%) } & \multicolumn{2}{|c|}{ Intake } & \multicolumn{2}{|c|}{ Contribution to RNI (\%) } & & \\
\hline & Mean & SD & Mean & SD & Mean & SD & Mean & SD & & \\
\hline Protein (g) & $56 \cdot 95$ & $34 \cdot 83$ & $79 \cdot 20$ & $48 \cdot 44$ & $63 \cdot 69$ & $17 \cdot 88$ & $88 \cdot 58$ & $24 \cdot 87$ & $-1 \cdot 116$ & $>0.05$ \\
\hline Lipids $(\mathrm{g})$ & $32 \cdot 50$ & $13 \cdot 76$ & $-^{\star}$ & & $39 \cdot 96$ & $5 \cdot 88$ & $-^{\star}$ & & $-3 \cdot 272$ & $<0.05$ \\
\hline Carbohydrate (g) & $211 \cdot 07$ & $65 \cdot 13$ & $-^{*}$ & & $252 \cdot 93$ & $58 \cdot 56$ & $-^{*}$ & & $-3 \cdot 097$ & $<0.05$ \\
\hline Energy (kcal) & $1289 \cdot 9$ & $379 \cdot 60$ & $61 \cdot 42$ & $18 \cdot 08$ & $536 \cdot 6$ & $252 \cdot 18$ & $73 \cdot 17$ & $12 \cdot 00$ & $-3 \cdot 319$ & $<0.05$ \\
\hline Fibre (g) & $9 \cdot 55$ & $5 \cdot 16$ & $-^{*}$ & & $24 \cdot 85$ & $3 \cdot 85$ & $-^{\star}$ & & $-4 \cdot 303$ & $<0.05$ \\
\hline Vitamin A $(\mu \mathrm{g})$ & $213 \cdot 75$ & $178 \cdot 27$ & $27 \cdot 80$ & $23 \cdot 18$ & $432 \cdot 10$ & $96 \cdot 34$ & $56 \cdot 19$ & $12 \cdot 53$ & $-6 \cdot 983$ & $<0.05$ \\
\hline Thiamin (mg) & 1.01 & 0.25 & $77 \cdot 69$ & $19 \cdot 23$ & $1 \cdot 57$ & $0 \cdot 82$ & $120 \cdot 77$ & $63 \cdot 08$ & $-4 \cdot 234$ & $<0.05$ \\
\hline Riboflavin (mg) & 0.74 & $0 \cdot 37$ & $52 \cdot 86$ & $26 \cdot 43$ & $1 \cdot 10$ & 0.42 & $78 \cdot 57$ & $30 \cdot 00$ & $-4 \cdot 169$ & $<0.05$ \\
\hline Vitamin C (mg) & $5 \cdot 09$ & $31 \cdot 81$ & 35.09 & $31 \cdot 81$ & $93 \cdot 26$ & $36 \cdot 37$ & $93 \cdot 26$ & $36 \cdot 37$ & $-7 \cdot 801$ & $<0.05$ \\
\hline Vitamin E (mg) & $9 \cdot 68$ & 4.53 & $69 \cdot 14$ & $32 \cdot 36$ & $13 \cdot 20$ & $6 \cdot 68$ & $94 \cdot 28$ & $47 \cdot 71$ & $-2 \cdot 821$ & $<0.05$ \\
\hline $\mathrm{Ca}(\mathrm{mg})$ & $288 \cdot 50$ & 223.98 & 28.85 & $22 \cdot 40$ & $447 \cdot 86$ & $166 \cdot 87$ & $44 \cdot 79$ & $16 \cdot 69$ & -3.533 & $<0.05$ \\
\hline $\mathrm{Mg}(\mathrm{mg})$ & $195 \cdot 80$ & $60 \cdot 43$ & 55.94 & $17 \cdot 27$ & $231 \cdot 46$ & $41 \cdot 78$ & $66 \cdot 13$ & 11.94 & $-3 \cdot 146$ & $<0.05$ \\
\hline $\mathrm{Fe}(\mathrm{mg})$ & $16 \cdot 80$ & $13 \cdot 38$ & $112 \cdot 00$ & $89 \cdot 20$ & $18 \cdot 48$ & $14 \cdot 70$ & $123 \cdot 00$ & 98.00 & -0.539 & $>0.05$ \\
\hline $\mathrm{Zn}(\mathrm{mg})$ & $9 \cdot 60$ & $4 \cdot 85$ & 83.48 & $42 \cdot 17$ & $11 \cdot 17$ & 6.93 & $97 \cdot 13$ & $60 \cdot 26$ & $-1 \cdot 200$ & $>0.05$ \\
\hline Se (mg) & $33 \cdot 18$ & $28 \cdot 20$ & $66 \cdot 36$ & $56 \cdot 4$ & $46 \cdot 09$ & $43 \cdot 77$ & $92 \cdot 18$ & $87 \cdot 54$ & $-1 \cdot 607$ & $>0.05$ \\
\hline
\end{tabular}

RNI, Recommended Nutrient Intake.

To convert kcal to kJ, multiply kcal value by $4 \cdot 184$.

${ }^{*}$ No specific standard; cannot calculate the percentage contribution to RNI.

Table 6 Comparison of baseline and follow-up rates of daily food intakes within the recommended range among diabetes patients ( $n$ 42) in Yakeshi, a remote city in northern China, April 2010-April 2011

\begin{tabular}{|c|c|c|c|c|c|c|c|}
\hline \multirow[b]{2}{*}{ Type of food } & \multirow[b]{2}{*}{ Recommended value } & \multicolumn{2}{|c|}{ Baseline } & \multicolumn{2}{|c|}{ Follow-up } & \multirow[b]{2}{*}{$\chi^{2}$} & \multirow[b]{2}{*}{$P$} \\
\hline & & $n$ & $\%$ & $n$ & $\%$ & & \\
\hline Grains (g) & 250-300 & 24 & $57 \cdot 14$ & 35 & $83 \cdot 33$ & $6 \cdot 89$ & $<0.05$ \\
\hline Vegetables (g) & 500 & 1 & $2 \cdot 38$ & 40 & $95 \cdot 24$ & $76 \cdot 19$ & $<0.05$ \\
\hline Meat $(g)$ & ) & & & & & & \\
\hline $\begin{array}{l}\text { Eggs }(\mathrm{g}) \\
\text { Beans }(\mathrm{g})\end{array}$ & \} $150-200$ & 21 & $50 \cdot 00$ & 29 & $69 \cdot 05$ & $3 \cdot 16$ & $>0.05$ \\
\hline Dairy (g) & 220 & 7 & $16 \cdot 67$ & 28 & $66 \cdot 67$ & $21 \cdot 60$ & $<0.05$ \\
\hline Fruits (g) & 400 & 3 & $7 \cdot 14$ & 12 & $28 \cdot 57$ & $9 \cdot 26$ & $<0.05$ \\
\hline
\end{tabular}

Table 7 Impact of education on glycaemic indices of diabetes patients ( $n$ 42) in Yakeshi, a remote city in northern China, April 2010-April 2011

\begin{tabular}{|c|c|c|c|c|c|c|}
\hline \multirow[b]{2}{*}{ Glycaemic index } & \multicolumn{2}{|c|}{ Baseline } & \multicolumn{2}{|c|}{ Follow-up } & \multirow[b]{2}{*}{$t$} & \multirow[b]{2}{*}{$P$} \\
\hline & Mean & SD & Mean & SD & & \\
\hline Fasting blood glucose $(\mathrm{mmol} / \mathrm{l})$ & $\begin{array}{r}6 \cdot 26 \\
10 \cdot 11\end{array}$ & $\begin{array}{l}1 \cdot 23 \\
1 \cdot 44\end{array}$ & $\begin{array}{l}5 \cdot 57 \\
8.61\end{array}$ & $\begin{array}{l}0.51 \\
1.08\end{array}$ & $\begin{array}{l}3 \cdot 359 \\
5 \cdot 380\end{array}$ & $\begin{array}{l}<0.05 \\
<0.05\end{array}$ \\
\hline
\end{tabular}

nutrition education can significantly improve the KAP level $^{(8)}$. Various nutrition education activities should be carried out in this region to help patients form reasonable eating habits and healthy nutrition behaviours, improve their glycaemic control abilities and thus reduce the occurrence of diabetes complications.

\section{Improvements of nutritional and eating education on diabetes-related knowledge, awareness, dietary intake and blood glucose control}

Findings from the baseline KAP questionnaire indicated that although patients' attitudes were positive, deficiencies existed in knowledge and practice. To improve their knowledge and practice, diabetes nutritional and eating education referring to healthy diet and self-management for diabetics was conducted.

In the present study we found that the rate of correct (positive) answers in the follow-up was significantly higher than in baseline, especially the rate of 'Do you know the concept of food exchange portion?' (increased from $2 \cdot 38 \%$ to $90 \cdot 48 \%$ ) and 'Do you deduct staple foods when you eat fruits?' (increased from $11 \cdot 90 \%$ to $100 \cdot 00 \%$ ). Education greatly improved patients' mastery of nutrition knowledge, the telephone follow-up strengthened their awareness of self-management and made patients participate in nutrition therapy actively. The rate of 'How often do you eat 
vegetables?' had no improvement $(P>0 \cdot 05)$ since this rate was very high at baseline.

As evidenced at baseline, patients' daily dietary intake was undesirable, the rate of diabetes patients with recommended daily intakes of food was low, especially for vegetables (2.38\%). After nutritional and eating education, the patients' dietary pattern improved; the percentage in terms of meeting recommendations for grains, vegetables, dairy and fruits increased remarkably $(P<0 \cdot 05)$. Although protein, $\mathrm{Fe}, \mathrm{Zn}$ and Se intakes showed no significant difference $(P>0.05)$, most daily nutrient intakes showed a significant increase $(P<0 \cdot 05)$, closer to the RNI standards. All of these results indicate that the described nutritional and eating education allowed patients to truly recognize the importance of rational nutrition therapy and improve their dietary pattern. Nutritional balance is essential to maintain health and central to preventing type 2 diabetes ${ }^{(14,15)}$. Diets high in fruits and vegetables demonstrate a strong and consistent pattern for providing benefits against diabetes ${ }^{(16)}$. Vegetables contain a large amount of dietary fibre, which can lower fasting blood glucose, postprandial blood glucose and improve glucose tolerance, so eating them in moderation is good for patients' glycaemic control. Fruits are high in sugars that are absorbed quickly; thus diabetics with poor fasting blood glucose control should eat them with caution and those with better fasting blood glucose control should also limit the quantity of fruit intake. When eating fruits, an appropriate amount of a staple food should be deducted. Low energy intake improves $2 \mathrm{~h}$ blood glucose profiles, insulin sensitivity and $\mathrm{Hb}^{(17)}$. The total energy intake should be calculated with a food exchange system according to patients' height, weight and labour intensity. Increasing the intake of carbohydrate can improve insulin sensitivity and glucose tolerance ${ }^{(18)}$, and energy provided by carbohydrate should account for $50-60 \%$ of total energy. Protein should provide 15-20\% of total energy and the proportion of high-quality protein should more than one-third of total protein intake. Meat, eggs and beans are all good sources of high-quality protein, but because most respondents in the present survey were elderly people and because animal foods contain high amounts of fat and cholesterol, they were suggested to eat more dairy, beans and related products. Dietary fat, especially too much saturated fat intake, is associated with impaired fasting glucose and insulin resistance ${ }^{(19)}$. Fat intake should be controlled to less than $30 \%$ of total energy. An adequate supply vitamins and minerals plays an important role in correcting metabolic disorders of diabetes and preventing complications. In the present study, patients' low intakes of vitamin A and Ca may relate to their eating habits and they should make a diet transition towards foods with high vitamin $\mathrm{A}$ and $\mathrm{Ca}$ and low fat and cholesterol content, such as milk, eggs, cod-liver oil, carrots, beans and their products.

Previous research has shown that patient education adds value to diabetes management and that specific interventions aimed at improving patients' knowledge can improve diabetes control ${ }^{(20)}$. In the follow-up, patients' blood glucose control was improved significantly compared with baseline. Both fasting blood glucose and $2 \mathrm{~h}$ postprandial blood glucose declined to the desirable standards which were constructed by the Chinese Diabetes Society ${ }^{(21)}$. The diabetes nutritional and eating education had made patients informed of correct nutrition knowledge on proper diet and following the healthy diet consistently made contributions to patients' blood glucose control.

A possible bias from patients' answers to the questions may exist in the current study. We adopted face-to-face interviews; however, diabetics could have misunderstood some of the questions because of a low level of education and kept something back when reporting nutrition knowledge, attitudes and practices. Thus answer bias was unavoidable in our interview-based investigation. Also, because of food diversity (different shapes, different cooking methods), participants had difficulties in assessing accurately the amount of food intake; thus dietary data collection bias may exist inevitably.

Despite these limitations, the present study is the first to report the nutrition knowledge, attitudes and practices and effect of nutritional and eating education among patients with type 2 diabetes in Yakeshi; no formal nutrition education has been made on the diabetics here before. This pilot study may provide a useful reference for further study on nutrition education and nutrition therapy of diabetes in outlying areas and more intensive nutrition intervention might be required to improve patients' dietary intakes and nutrition management of type 2 diabetes.

\section{Acknowledgements}

Sources of funding: This work was supported by the National Science Foundation of China (No. 81172650). The funder had no role in the design, analysis or writing of this article. Conflict of interest: None of the authors had any conflicts of interest in this work. Ethics: The study was approved by the Ethical Committee of Harbin Medical University. Authors' contributions: Y.W. was the Principal Investigator of the project and contributed to the study design, writing, revising and final approval of the manuscript. H.W., Z.F.S. and Y.H.B. contributed equally to the study. The manuscript and revised paper were written mainly by H.W. and Z.F.S. L.Z. took part mainly in the investigation and data analysis. Acknowledgements: The authors sincerely acknowledge all of the investigators and their staff for participation in this survey and thank Xiangkun Cao and Antonia Frank for language editing of the revised manuscript.

\section{References}

1. Wild S, Roglic G, Green A et al. (2004) Global prevalence of diabetes: estimates for the year 2000 and projections for 2030. Diabetes Care 27, 1047-1053. 
2. Yang W, Lu J, Weng J et al. (2010) Prevalence of diabetes among men and women in China. $N$ Engl J Med 362, 1090-1101.

3. Turner R, Cull C \& Holman R (1996) United Kingdom Prospective Diabetes Study 17: a 9-year update of a randomized, controlled trial on the effect of improved metabolic control on complications in non-insulin-dependent diabetes mellitus. Ann Intern Med 124, 136-145.

4. Pastors JG, Warshaw H, Daly A et al. (2002) The evidence for the effectiveness of medical nutrition therapy in diabetes management. Diabetes Care 25, 608-613.

5. Li XQ (2003) Investigation and analysis of the status of implementation of diabetes nutrition education. Chinese J Nurs 38, 3 .

6. Chapman-Novakofski K \& Karduck J (2005) Improvement in knowledge, social cognitive theory variables, and movement through stages of change after a community-based diabetes education program. I Am Diet Assoc 105, 1613-1616.

7. Wang G \& Yang Y (2009) Chinese Food Composition. Beijing: Peking University Medical Press.

8. Zhao RF \& Xu WP (2007) Study of diet nutrition knowledgeattitude-practice (KAP). J Pract Diabetol 3, 3.

9. Kafatos A \& Codrington CA (1999) Nutrition and diet for healthy lifestyles in Europe: the 'Eurodiet' Project. Public Health Nutr 2, 327-328.

10. Moore H \& Adamson AJ (2002) Nutrition interventions by primary care staff: a survey of involvement, knowledge and attitude. Public Health Nutr 5, 531-536.

11. Zhang Y \& Qiao ZM (2008) Discussion of medical nutrition therapy mode on the young and middle-aged patients with diabetes. Chinese J Clin Healthcare 11, 2.
12. Funnell MM, Brown TL, Childs BP et al. (2012) National standards for diabetes self-management education. Diabetes Care 35, Suppl. 1, S101-S108.

13. Nilsson PM, Johansson SE \& Sundquist J (1998) Low educational status is a risk factor for mortality among diabetic people. Diabet Med 15, 213-219.

14. Tuomilehto J, Lindstrom J, Eriksson JG et al. (2001) Prevention of type 2 diabetes mellitus by changes in lifestyle among subjects with impaired glucose tolerance. $N$ Engl J Med 344, 1343-1350.

15. Knowler WC, Barrett-Connor E, Fowler SE et al. (2002) Reduction in the incidence of type 2 diabetes with lifestyle intervention or metformin. $N$ Engl J Med 346, 393-403.

16. Jimenez-Cruz A, Bacardi-Gascon M \& Jones EG (2002) Consumption of fruits, vegetables, soft drinks, and highfat-containing snacks among Mexican children on the Mexico-US border. Arch Med Res 33, 74-80.

17. Boden G, Sargrad K, Homko C et al. (2005) Effect of a low-carbohydrate diet on appetite, blood glucose levels, and insulin resistance in obese patients with type 2 diabetes. Ann Intern Med 142, 403-411.

18. Lu M (2000) Investigation and analysis of dietary intake and nutritional status of diabetic patients. Parenteral Enteral Nutr 7, 150-152.

19. Feskens EJ \& Kromhout D (1990) Habitual dietary intake and glucose tolerance in euglycaemic men: the Zutphen Study. Int J Epidemiol 19, 953-959.

20. Asha RPA \& Mohan V (2004) Evidence for benefits from diabetes education program. Int J Diabetes Devel Countries 24, 96-102.

21. Chinese Diabetes Society (2011) China Guideline for type 2 diabetes. Chinese J Front Med Sci 3, 55. 